of Darwin on the selection and evolution of animals under domestication, interspersed with many new points of view and observations on reproduction and livestock breeding.

JOHN HAMMOND

\section{AN INTRODUCTION TO MODERN PHYSICS}

From Galileo to the Nuclear Age

An Introduction to Physics. By Prof. Harvey Brace Lemon. Revised edition of "From Galileo to Cosmic Rays". Pp. xviii +45l. (Chicago: University of Chicago Press; London: Cambridge University Press, 1946.) 21s. net.

A NY book that aims at presenting a readable A account of modern science is to be welcomed, and Dr. Lemon's work on the development of physics from Galileo to the present time has this objective specially in view. Such a study, he claims, should have "something of that human interest that attaches to great personalities, but most of all it should try to show explicitly and implicitly how a great scientific field of thought has come into being. Moreover it should indicate the satisfaction enjoyed by those who participate in such a development of thought, as well as its practical advantages to mankind." Even a cursory glance at this volume shows how far the author has departed from conventional academic form, in order to interest his readers. His colloquial and homely style, together with many well-produced illustrations (sometimes stereophotographs) of a topical and frequently unconventional type, are designed to meet the needs of first-year university students in other faculties who have little background knowledge of the physical sciences. Though based on the curriculum of the University of Chicago, Prof. Lemon's treatment will undoubtedly appeal to similar students elsewhere, and, indeed, to the general reader.

The book is divided into five parts, dealing respectively with mechanics, heat, electricity and magnetism, electricity and matter, waves and radiation. Attention is directed to the underlying importance of the work of Galileo and Newton, and the first part includes successive chapters on work, energy, conservation of energy, power, and con. cludes with a convincing treatment of the problems of atmosphere and hydrosphere. Prof. Lemon has added to the general interest of his subject by including references to the origin of the Fahrenheit scale, the measurement of temperature by electrical means, and so on: the section on heat onds with a chapter on kinetic theory. Part 3, "Electricity and Magnetism", contains the ground-work study necessary for the appreciation of modern developments. In particular, a helpful approach to 'lines of force' is made by consideration of a gravitational field. In the last two parts of the book, the reader is introduced to an interesting survey of the conduction of electricity through gases, photo-electric and thermionic effects, electrons, radioactivity, electromagnetic waves, and atomic structure. In the part especially dealing with waves, a chapter on sound is inserted.

Though "From Galileo to the Nuclear Age" is primarily a survey of the modern achievements of physics and their dependence on the work of pioneers, the author does not ignore the implications and possibilities of science at this time. "Will man be able in the future so to conduct his political, social, and economic life as to put an end to war and prevent for the future the much greater powers of destruction that soon all nations will possess? Unless this can be accomplished the darkest of all ages surely lies ahead; the rare joy that in the past has gone with the acquisition of knowledge will be known no more. . . . Let us devoutly hope that in some way these problems may be met in time so that future generations again can get some joy from probing still more deeply into the heart of Nature." H. D. ANTHony

\section{DISSECTION OF THE CAT}

\section{Functional Anatomy of the Mammal}

A Guide to the Dissection of the Cat and an Intro. duction to the Structural and Functional Relationship between the Cat and Man. By Asst. Prof. W. James Leach. .(McGraw-Hill Publications in the Zoological Sciences.) Pp. viii +231. (New York and London: McGraw-Hill Book Co. Inc., 1946.) 12s. $6 d$.

WE choice of a mammalian type suitable for dissection as an introduction to human anatomy and physiology has usually fallen on the rabbit or the rat. The rodent, however, is in many ways less suitable than the carnivore, which is less primitive and is structurally a little nearer to man. We welcome, therefore, this book on the cat as an elementary account of a common and easily obtained mammal.

Constant comparisons with human anatomy and physiology are stressed throughout, and there are many useful summaries. The effects of posture on modifications of structure, especially as regards the upright habit in man, are referred to in an interesting way that makes the book read well, and relieves it from the tedium of names and descriptions so charac. teristic of the average text-book. At the end of many of the chapters, problems relating to physiology; mechanics of joints and muscles, and surgery are suggested as a stimulus to the future nurse or medical man.

The systems of the body are dealt with in turn, using the injected cat for dissection. Has the author, however, used the just-born kitten instead of the adult cat? For many of the organs it proves much easier, although so much smaller. This is particularly the case with regard to the sympathetic nervous system, which can be demonstrated with ease owing to the relatively large size of the ganglia and the gelatinous nature of the connective tissue. The difference between the foctal and adult circulations can also be elucidated.

The original line block illustrations are excellent, especially those relating to the skeleton and muscles. The labelling in full is also good. But the half-tone reproductions of drawings by John Trainor do not mix well with the others, and illustrations from other authors have not always been correlated with the text, so that the junior student for whom the book is intended will sometimes find it difficult to recognize the parts under their Latin names. The author's Latin is irregular; foramen ovale changes in the course of the book to foramen ovalis, while fossa ovalis becomes fossa ovale; the plural of plexus is wrongly given as plexi. These are small points that could be corrected in a later edition.

As with all MeGraw-Hill publications the book is well produced and the price is reasonable.

N. B. EALES 